\title{
CobaltCatalyzed Dehydrogenative Coupling of Amines into Imines
}

\author{
Bottaro, Fabrizio; Takallou, Ahmad; Chehaiber, Ahmad; Madsen, Robert
}

Published in:

European Journal of Organic Chemistry

Link to article, DOI:

10.1002/ejoc.201901462

Publication date:

2019

Document Version

Peer reviewed version

Link back to DTU Orbit

Citation (APA):

Bottaro, F., Takallou, A., Chehaiber, A., \& Madsen, R. (2019). CobaltCatalyzed Dehydrogenative Coupling of Amines into Imines. European Journal of Organic Chemistry, 2019(42), 7164-7168.

https://doi.org/10.1002/ejoc.201901462

\section{General rights}

Copyright and moral rights for the publications made accessible in the public portal are retained by the authors and/or other copyright owners and it is a condition of accessing publications that users recognise and abide by the legal requirements associated with these rights.

- Users may download and print one copy of any publication from the public portal for the purpose of private study or research.

- You may not further distribute the material or use it for any profit-making activity or commercial gain

- You may freely distribute the URL identifying the publication in the public portal

If you believe that this document breaches copyright please contact us providing details, and we will remove access to the work immediately and investigate your claim. 


\title{
Cobalt-Catalyzed Dehydrogenative Coupling of Amines into Imines
}

\author{
Fabrizio Bottaro, ${ }^{[\mathrm{a}]}$ Ahmad Takallou, ${ }^{[\mathrm{a}]}$ Ahmad Chehaiber, ${ }^{[\mathrm{a}]}$ and Robert Madsen ${ }^{\star[a]}$
}

\begin{abstract}
Primary amines have been subjected to an acceptorless dehydrogenative homo- and heterocoupling into imines with a cobalt catalyst. The catalytically active species are composed of cobalt nanoparticles, which are generated in situ by heating $\mathrm{Co}_{2}(\mathrm{CO})_{8}$ in the presence of trioctylphosphine oxide as a surfactant. The nanoparticles have been characterized by transmission electron microscopy where the image showed spherical and small particles with a narrow size distribution. The catalyst can be recovered and used again with essentially no effect on the yield. The catalyst can also be used for the dehydrogenative coupling of alcohols and amines into imines.
\end{abstract}

\section{Introduction}

Dehydrogenative transformations proceed with the release of hydrogen gas and have seen much development over the past 15 years. ${ }^{[1-3]}$ The reactions have mostly been carried out with alcohols to afford imines, amides, esters, carboxylic acids and various heterocycles. Initially, the transformations were mainly catalyzed by complexes of ruthenium and iridium, ${ }^{[1]}$ but recently catalysts based on several Earth-abundant metals such as manganese, iron and cobalt have also been developed to mediate the dehydrogenations..$^{[2]}$

Besides alcohols, dehydrogenative reactions have also been performed with amines to generate imines and nitriles, although these are more challenging transformations with only a few known examples. Two ruthenium complexes with a PNP pincer and an $\mathrm{N}$-heterocyclic carbene ligand, respectively, have been shown to catalyze the homo- and heterocoupling of primary amines into imines at temperatures between 115 and $160{ }^{\circ} \mathrm{C} .{ }^{[4]}$ The same transformations have been carried out with $0.5 \%$ of $\mathrm{Pd}$-doped hydrotalcites in refluxing xylene, with $5 \%$ of $\mathrm{Pd} / \mathrm{C}$ in dimethylacetamide at $120{ }^{\circ} \mathrm{C}$, and with $10 \%$ of a rhodium catalyst under photolytic conditions. ${ }^{[5]}$ In an unusual case, imine formation has also been observed upon refluxing benzylamine in toluene with $20 \%$ of an aluminum NNN pincer complex. ${ }^{[6]}$ Likewise, the dehydrogenation of primary amines into nitriles has been achieved with a ruthenium NNN pincer complex and a ruthenium naphthyridine-pyrazole complex with the liberation of 2 equiv. of hydrogen gas. ${ }^{[7]}$ Due to the facile reduction of imines with hydrogen gas, a more common reaction pathway under

[a] Department of Chemistry

Technical University of Denmark

2800 Kgs. Lyngby (Denmark)

E-mail: rm@kemi.dtu.dk

https://www.kemi.dtu.dk

Supporting information for this article is given via a link at the end of the document.((Please delete this text if not appropriate)) these conditions is the coupling of primary amines into secondary amines with the release of ammonia where the imine is only serving as an intermediate. This transformation has been catalyzed by a number of homogeneous ruthenium ${ }^{[8]}$ and iridium $^{[9]}$ catalysts as well as heterogeneous platinum, ${ }^{[10]}$ palladium ${ }^{[11]}$ and copper ${ }^{[12]}$ catalysts.

In 2013, the first cobalt catalysts were presented for the dehydrogenation of alcohols consisting of a homogeneous PNP pincer complex ${ }^{[13]}$ and a heterogeneous $\mathrm{Co} / \mathrm{TiO}_{2}$ catalyst. ${ }^{[14]}$ Since then, several cobalt pincer complexes have been developed for the alcohol dehydrogenation ${ }^{[15]}$ and recently the scope was extended to unsupported cobalt nanoparticles ${ }^{[16]}$ and a PPPN cobalt complex ${ }^{[17]}$ which were both shown to catalyze the conversion of alcohols into ketones. Furthermore, $10 \%$ of $\mathrm{Cp}^{*} \mathrm{Co}(\mathrm{CO}) \mathrm{I}_{2} / \mathrm{PCy}_{3}$ has lately been used to catalyze the $\mathrm{N}$ alkylation of amines with secondary alcohols. ${ }^{[18]}$ On the contrary, the dehydrogenation of amines has only been described in two cases with a cobalt catalyst and only for converting primary amines into secondary amines. With $2 \%$ of a homogeneous cobalt pincer complex the homo- and heterocoupling of primary amines was achieved in toluene at $120{ }^{\circ} \mathrm{C} \cdot{ }^{[19]}$ In addition, $0.5 \%$ of a heterogeneous bimetallic $\mathrm{Co}_{2} \mathrm{Rh}_{2} / \mathrm{C}$ catalyst mediated the homocoupling of primary amines in toluene at $180^{\circ} \mathrm{C} .^{[20]}$ Thus, the acceptorless dehydrogenation of amines with cobalt catalysts and other non-noble metal catalysts is still very poorly developed. ${ }^{[21]}$ This prompted us to initiate an investigation into dehydrogenations with this metal, which led to the discovery of cobalt nanoparticles as catalysts for the amine dehydrogenation. ${ }^{[22]}$ Recently, different preparations of cobalt nanoparticles have seen a number of applications in the opposite reaction, i.e. the hydrogenation of various double bonds with hydrogen gas. ${ }^{[23]}$ Furthermore, nanoparticle catalysts based on other Earth-abundant metals have been used for both hydrogenation and dehydrogenation reactions especially iron oxide and nickel catalysts. ${ }^{[24]}$

Herein, we describe the first example of a cobalt-catalyzed acceptorless dehydrogenation of amines into imines. The transformation is achieved with in situ formed cobalt nanoparticles which can also be used for the coupling of alcohols and amines into imines. ${ }^{[25]}$

\section{Results and Discussion}

The reaction was discovered while attempting to develop a more convenient in situ formed catalyst system. For this purpose, $\mathrm{Co}_{2}(\mathrm{CO})_{8}$ was selected as the cobalt source and first reacted with 2-naphthalenemethanol and benzylamine in refluxing toluene. Various phosphines were included as ligands and low to moderate yields of $\mathrm{N}$-(2-naphthalenylmethylene) benzylamine were obtained. However, and more importantly, black magnetic 
particles were formed during the transformations, which could indicate that cobalt nanoparticles were generated and responsible for the catalytic reaction. Thermal decomposition of $\mathrm{CO}_{2}(\mathrm{CO})_{8}$ is a common method for preparing cobalt nanoparticles and is usually performed at a higher temperature. ${ }^{[26]}$ For that reason, we decided to repeat the coupling in refluxing mesitylene in the absence of any ligands. Surprisingly, this experiment now produced a 3:4 mixture of the two imines $N$-(2-naphthalenylmethylene) benzylamine and $N$ benzylidene benzylamine where the formation of the latter is due to a dehydrogenative self-coupling of benzylamine. Generally, alcohols are dehydrogenated much more readily than primary amines and the result could suggest that cobalt nanoparticles are particularly well-suited for amine dehydrogenations. As a result, it was decided to optimize this reaction and to understand the nanoparticle formation under these conditions.

Benzylamine was selected for developing the imination reaction and the first experiment with $\mathrm{Co}_{2}(\mathrm{CO})_{8}$ gave complete conversion into $\mathrm{N}$-benzylidene benzylamine. However, it was also quickly realized that this reaction was not always reproducible which is most likely due to the poor control of the nanoparticle formation. Usually, cobalt nanoparticles are formed in the presence of a surfactant to ensure a uniform crystal growth and shape as well as preventing agglomeration and oxidation. ${ }^{[27]}$ Thus, the two common surfactants oleic acid and trioctylphosphine oxide (TOPO) were included in the optimization and more reproducible results were now obtained (Table 1). The amounts of the two agents were varied with $1 \%$ of $\mathrm{Co}_{2}(\mathrm{CO})_{8}$ and the reactions with TOPO gave consistently higher yields than with oleic acid (entries 1-5). Accordingly, TOPO was selected for controlling the nanoparticle formation and to improve the yield the amount of $\mathrm{Co}_{2}(\mathrm{CO})_{8}$ was increased (entries 6 and 7$)$. With $3 \%$ of $\mathrm{Co}_{2}(\mathrm{CO})_{8}$ an almost quantitative yield of the imine was obtained and these conditions were therefore selected as the general protocol for the dehydrogenative coupling. No further dehydrogenation to benzonitrile was observed in any of the experiments. The importance of the nanoparticle formation was confirmed by two control experiments using $3 \%$ of commercial cobalt powder (2 microns) and $\mathrm{Co}_{3} \mathrm{O}_{4}$ nanopowder $(<50 \mathrm{~nm})$, respectively. Very little conversion of benzylamine was achieved in these two cases where only $10-15 \%$ yield of the imine was obtained.

Table 1. Optimization of cobalt-catalyzed dehydrogenation. ${ }^{[\mathrm{a}]}$

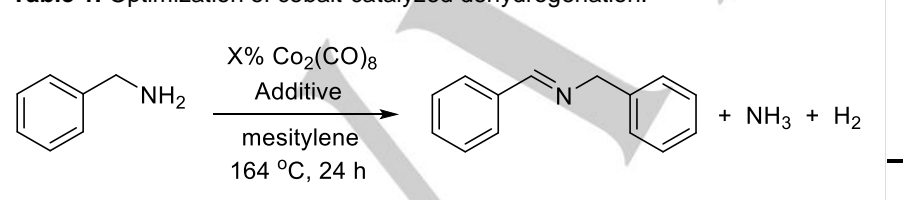

\begin{tabular}{llll}
\hline Entry & $\mathrm{X}$ & Additive & Yield $[\%]^{[\mathrm{b}]}$ \\
\hline 1 & 1 & Oleic acid $(0.01 \mathrm{~mL})$ & 37 \\
2 & 1 & Oleic acid $(0.02 \mathrm{~mL})$ & 40 \\
3 & 1 & Oleic acid $(0.01 \mathrm{~mL})+$ TOPO $(10 \mathrm{mg})$ & 68 \\
4 & 1 & TOPO $(5 \mathrm{mg})$ & 77
\end{tabular}

\begin{tabular}{llll}
5 & 1 & TOPO $(10 \mathrm{mg})$ & 64 \\
6 & 2 & TOPO $(10 \mathrm{mg})$ & 83 \\
7 & 3 & TOPO $(10 \mathrm{mg})$ & 97 \\
\hline
\end{tabular}

[a] Reaction conditions: Benzylamine (2 mmol), $\mathrm{Co}_{2}(\mathrm{CO})_{8}(\mathrm{X} / 100 \mathrm{mmol})$, additive, mesitylene $(2 \mathrm{~mL})$, reflux, $24 \mathrm{~h}$. [b] Determined by GC.

Next, the optimized procedure was applied to a number of primary amines to investigate the scope and limitations of the method. First, several amines were subjected to the homocoupling and the imine products were isolated by flash chromatography (Table 2). This produced compound 1 in $79 \%$ yield while the corresponding $p$-methyl component 2 was obtained in $82 \%$ yield. $p$-Fluoro-, $p$-chloro- and $p$-bromobenzyl amine furnished the homocoupled imines $3-5$ in $68-72 \%$ yield with no sign of any competing dehalogenation reactions. A slightly lower yield was observed for $p$-phenylbenzyl amine where imine 6 was isolated in 53\% yield. o-Methylbenzyl amine and 2-thiophenemethyl amine gave products 7 and 8 in 39 and $44 \%$ isolated yield, respectively. Aliphatic amines, on the other hand, reacted slower and the products were generally too unstable to be isolated by flash chromatography. In these cases, cyclohexyl amine and heptan-1-amine gave the corresponding imines 9 and 10 in 49 and $44 \%$ GC yield. Small amounts of unreacted primary amine were observed in the syntheses of 6 10 and thus accounts for the more moderate yields of these imines.

Table 2. Cobalt-catalyzed dehydrogenative homocoupling of amines. ${ }^{[a]}$

$$
\begin{aligned}
\mathbf{2}(\mathrm{R}=\mathrm{Me}), 82 \% \\
\mathbf{3}(\mathrm{R}=\mathrm{F}), 68 \% \\
\mathbf{4}(\mathrm{R}=\mathrm{Cl}), 70 \% \\
\mathbf{6}(\mathrm{R}=\mathrm{Br}), 72 \% \\
\mathbf{6}=\mathrm{Ph}), 53 \%(67 \%)^{[\mathrm{b}]}
\end{aligned}
$$

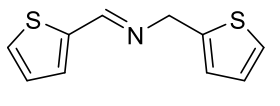

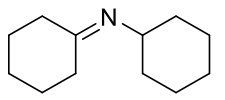

9, $(49 \%)^{[\mathrm{c}]}$

[a] Reaction conditions: Primary amine $(2 \mathrm{mmol}), \mathrm{Co}_{2}(\mathrm{CO})_{8}(0.3 \mathrm{mmol}), \mathrm{TOPO}$ $(10 \mathrm{mg})$, mesitylene $(2 \mathrm{~mL})$, reflux, $24 \mathrm{~h}$. [b] Yield in parenthesis was determined by NMR. [c] Yield in parenthesis was determined by GC.

The reactivity difference between the primary amines also makes it possible to perform heterocoupling reactions (Table 3). To promote the formation of the cross coupling products, a slight excess of the amine that is not dehydrogenated was employed. Again, the imines were isolated by flash chromatography and 
due to their modest stability several yields were also determined by NMR and GC. Benzylamine and the $p$-methyl, $p$-fluoro and $p$ bromo counterparts were reacted with $p$-anisidine to afford the corresponding benzylic imines $\mathbf{1 1 - 1 4}$ in $54-71 \%$ isolated yield No dehalogenation was observed as a side reaction with the $p$ bromo compound. $p$-Methyl- and $p$-fluorobenzyl amine reacted likewise with aniline to give imines 15 and 16 in 73 and 51\% yield, respectively, In the same way, $p$-fluoro- and $p$ methylaniline were coupled with $p$-methylbenzylamine to afford 17 and 18 in 57 and $44 \%$ isolated yield. The nature of the substituents on the aromatic ring of the benzylamine and the aniline moiety did not seem to have a significant influence on the outcome of the heterocoupling. The reaction could also be applied to the cross coupling with aliphatic amines as shown for the condensation of octane-1-amine and cyclohexyl amine with benzylamine to furnish imines 19 and 20 in 60 and $57 \%$ yield. In the same way, octane-1-amine was coupled with 1-adamantyl amine to give imine 21 in $57 \%$ GC yield. In all cases, small amounts of a byproduct from homocoupling of the amine undergoing the dehydrogenation was also observed. Secondary amines, on the other hand, were not detected as byproducts in any of the experiments in Table 2 and 3 indicating that the cobalt catalyst is not able to mediate the hydrogenation of the Schiff base functionality.

Table 3. Cobalt-catalyzed dehydrogenative heterocoupling of amines. ${ }^{[a]}$ $\mathrm{R}_{\mathrm{NH}_{2}}+\mathrm{H}_{2} \mathrm{~N}-\mathrm{R}^{\prime} \stackrel{3 \% \mathrm{Co}_{2}(\mathrm{CO})_{8} \text {, TOPO }}{\stackrel{\text { mesitylene, } 164{ }^{\circ} \mathrm{C}, 24 \mathrm{~h}}{\longrightarrow}}$ $\overbrace{}^{\curvearrowright} N^{-}$<smiles>[R]c1ccc(/C=N/c2ccc(OC)cc2)cc1</smiles><smiles></smiles>
$15(\mathrm{R}=\mathrm{Me}), 73 \%$ $16(\mathrm{R}=\mathrm{F}), 51 \%(71 \%)^{[\mathrm{b}]}$

$$
\begin{aligned}
& 11(R=H), 69 \% \\
& 12(R=M e), 71 \% \\
& 13(R=F), 59 \%(62 \%)^{[b]} \\
& 14(R=B r), 54 \%(75 \%)^{[b]}
\end{aligned}
$$
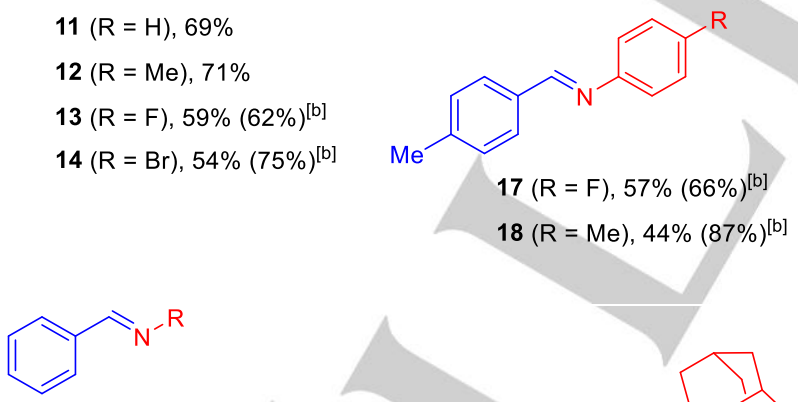

$19\left(\mathrm{R}=\left(\mathrm{CH}_{2}\right)_{7} \mathrm{CH}_{3}\right), 60 \%$ $20(R=C y), 57 \%(63 \%)^{[b]}$

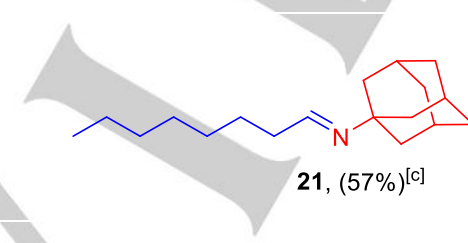

[a] Reaction conditions: Blue amine (1 mmol), red amine (1.5 mmol), $\mathrm{Co}_{2}(\mathrm{CO})$ (0.3 mmol), TOPO (10 mg), mesitylene $(2 \mathrm{~mL})$, reflux, $24 \mathrm{~h}$. [b] Yield in parenthesis was determined by NMR. [c] Yield in parenthesis was determined by $\mathrm{GC}$.

Although the catalyst system has been specifically optimized for the dehydrogenative coupling of amines, it was decided to briefly investigate again the more common dehydrogenation of alcohols. In this case, a slight increase in the loading of
$\mathrm{Co}_{2}(\mathrm{CO})_{8}$ and TOPO to $5 \%$ was necessary to ensure full conversion of the alcohol, since the coupling between benzyl alcohol and cyclohexylamine with $3 \%$ of $\mathrm{Co}_{2}(\mathrm{CO})_{8}$ only gave a $62 \%$ GC yield. No improvement was observed when various additives (bases and desiccants) were included in the reaction. Thus, with this modification benzylic alcohols could also be employed in the dehydrogenative coupling with amines (Table 4). Benzyl alcohol was reacted with cyclohexyl amine, aniline and $p$ anisidine to afford the corresponding imines $22-24$ in $60-89 \%$ isolated yields, while cyclohexyl amine was also reacted with $p$ nitrobenzyl alcohol and 2-naphthalenemethanol to furnish the Schiff bases 25 and 26 in 51 and $60 \%$ yield, respectively.

Table 4. Cobalt-catalyzed dehydrogenative coupling of alcohols and amines. ${ }^{[a]}$

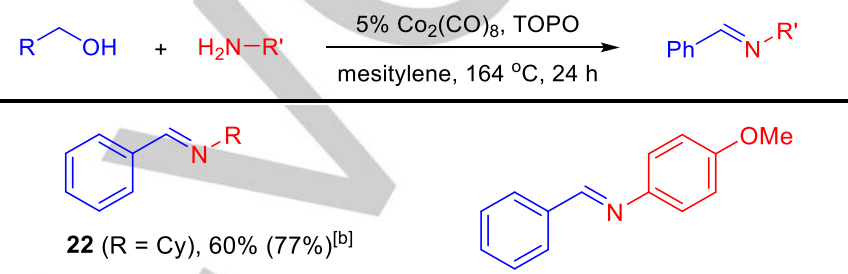
$23(\mathrm{R}=\mathrm{Ph}), 65 \%$ $24,89 \%$

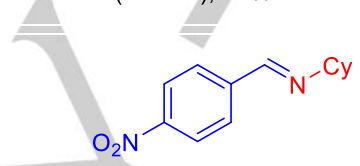

$25,51 \%$

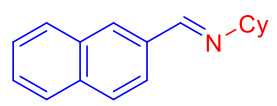

26, $60 \%$

[a] Reaction conditions: Alcohol (1 mmol), amine $(1.1 \mathrm{mmol}), \mathrm{Co}_{2}(\mathrm{CO})_{8}(0.5$ $\mathrm{mmol})$, TOPO (20 mg), mesitylene $(2 \mathrm{~mL})$, reflux, $24 \mathrm{~h}$. [b] Yield in parenthesis was determined by GC.

The gas evolution was measured for the optimized experiment in Table 1, entry 7 . The gaseous mixture was passed through water to absorb ammonia giving rise to $30 \mathrm{~mL}$ $(1.2 \mathrm{mmol})$ of gas from $2 \mathrm{mmol}$ of benzylamine. Theoretically only $1 \mathrm{mmol}$ of gas should have been collected, but most likely the released ammonia was not completely absorbed in the water bath. The gas was subsequently identified as dihydrogen which confirms the acceptorless dehydrogenative pathway of the transformation. The addition of 2,6-di-tert-butyl-4-methylphenol (BHT) had no influence on the conversion indicating that a radical pathway is not involved in the reaction. The addition of mercury, on the contrary, completely halted the conversion into the product, which supports the presence of cobalt nanoparticles as the catalytically active species. The mechanism for the alcohol dehydrogenation on cobalt nanoparticles has previously been investigated by DFT calculations ${ }^{[16]}$ where the favored route involved initial $\mathrm{O}-\mathrm{H}$ bond cleavage to form a cobalt alkoxide followed by breaking of the $\mathrm{C}-\mathrm{H}$ bond to give the carbonyl compound. A similar pathway may be operating in the present dehydrogenation of primary amines.

The black magnetic particles formed during the reactions could be isolated by depositing on the stir bar. This was performed for the reaction in Table 1, entry 7 and the particles were then used again to catalyze the same transformation. Full conversion of benzylamine was also observed with the recycled particles and the procedure was repeated a total of three times 
to afford $N$-benzylidene benzylamine in $93-97 \%$ GC yield. Thus, the cobalt catalyst can be recovered and used again from the experiments without significantly changing the yield of the dehydrogenative transformation.

To gain more information about the morphology of the particles, characterization by transmission electron microscopy (TEM) was also carried out. The TEM image of the precipitate from the reaction in Table 1 , entry 7 showed spherical and monodispersed particles with a small average diameter of 2.2 $\mathrm{nm}$ and a narrow size distribution (Figure 1). The crystalline nature of the particles was confirmed by X-ray diffraction (XRD) which uncovered broad peaks at $44.4^{\circ}$ and $51.8^{\circ}$ most likely corresponding to the (111) and (200) planes of the facecentered cubic (fcc) phase of cobalt. ${ }^{[16]}$ The fcc crystal structure is presumably formed due to the small size of the nanoparticles ${ }^{[28]}$ which is also the reason for the broadening of the signals. The presence and distribution of cobalt in the particles was also confirmed by elemental mapping with energy disperse X-ray spectroscopy (EDS).
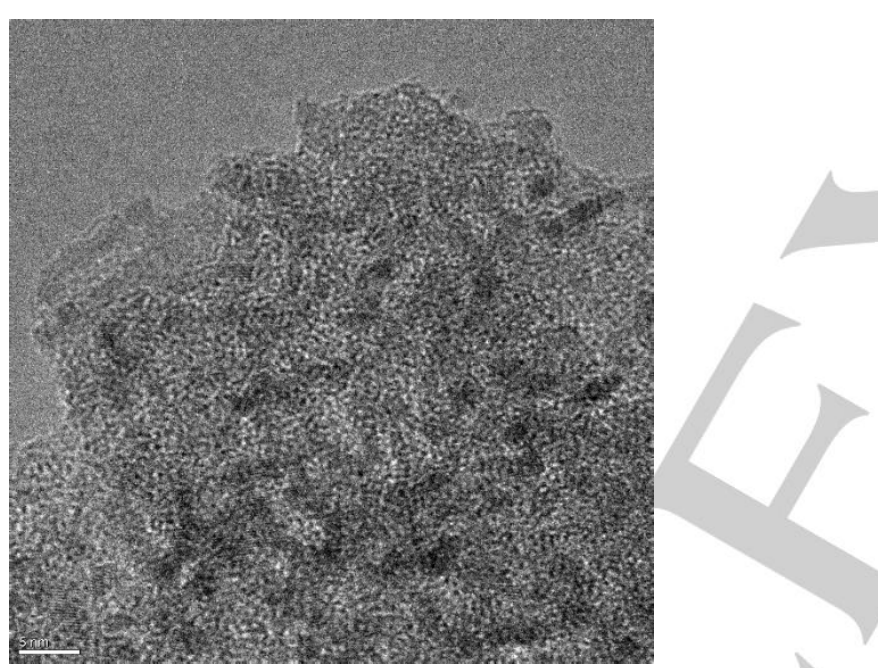

Figure 1. TEM image of cobalt nanoparticles (bar $5 \mathrm{~nm}$ ).

In Table 1 the experiments with oleic acid as surfactant gave inferior yields as compared to the use of TOPO. To understand this difference TEM images were also obtained of the precipitate formed from the reactions in Table 1, entry 1 and Table 1, entry 3. In the first case, where only oleic acid is used to control the particle formation, the image revealed small agglomerates of nanoparticles with an average size of about $20 \mathrm{~nm}$. In the second case, where both oleic acid and TOPO are employed as surfactants, the image showed a mixture of spherical nanoparticles with a wide size distribution and nanorods of different length. The mixture of oleic acid and TOPO has previously been shown to promote the formation of cobalt particles ranging from spherical to rod-like in shape depending on the ratio of the surfactants. ${ }^{[26 c]}$ Under our conditions, however, the morphology was poorly controlled giving rise to a wide size distribution. Thus, the use of TOPO as the surfactant is vital to secure the formation of small nanoparticles with a narrow size distribution, which appears to be essential for achieving the desired dehydrogenative transformation.

\section{Conclusions}

In summary, we have described cobalt nanoparticles for catalyzing the acceptorless homo- and heterocoupling of amines into imines. The catalyst is generated in situ from $\mathrm{Co}_{2}(\mathrm{CO})_{8}$ and TOPO and can also be used for the coupling of alcohols and amines into imines. The nanoparticles can be recovered and used again without significantly changing the yield of the reactions. Their morphology has been characterized by transmission electron microscopy where small spherical particles with a narrow size distribution were shown to give the best results.

\section{Experimental Section}

General Information: All commercially available reagents were purchased from Sigma-Aldrich or Strem Chemicals and were used as received. Mesitylene was reagent grade, stored over activated $4 \AA$ molecular sieves for 24 to $48 \mathrm{~h}$ and degassed through 3 freeze-pumpthaw cycles under an atmosphere of nitrogen. Gas chromatography was performed on a Shimadzu GCMS-QP2010S instrument fitted with an Equity $5,30 \mathrm{~m} \times 0.25 \mathrm{~mm} \times 0.25 \mu \mathrm{m}$ column. Helium was used as the carrier gas and ionization was performed by electron impact $(70 \mathrm{eV})$. Flash column chromatography separations were performed on silica gel $60(40-63 \mu \mathrm{m})$. NMR spectra were recorded on a Bruker Ascend 400 spectrometer. Chemical shifts were measured relative to the signals of residual $\mathrm{CHCl}_{3}\left(\delta_{\mathrm{H}}=7.26 \mathrm{ppm}\right)$ and $\mathrm{CDCl}_{3}(\delta \mathrm{C}=77.16 \mathrm{ppm})$. The TEM analysis was performed with a FEI Tecnai $\mathrm{T} 20 \mathrm{G}^{2}$ transmission electron microscope operating at $200 \mathrm{kV}$. The XRD was measured in transmission mode with a HUBER G670 Guinier camera using $\mathrm{Cu}-\mathrm{K} \alpha$ radiation from a focusing quarts monochromator.

General Procedure for the Homo- and Heterocoupling of Amines: An oven-dried Schlenk tube $(24 \times 150 \mathrm{~mm})$ was charged with $\mathrm{Co}_{2}(\mathrm{CO})_{8}(10$ $\mathrm{mg}, 0.03 \mathrm{mmol})$, trioctylphosphine oxide (TOPO) $(10 \mathrm{mg}, 0.026 \mathrm{mmol})$ and a cylindrical stir bar $(10 \times 6 \mathrm{~mm})$. The tube was inserted into a Radleys carousel, vacuum was applied and the tube was filled with nitrogen (repeated 3 times). Degassed mesitylene $(2 \mathrm{~mL})$ was added with a syringe through the septum and the reaction vessel was heated to $164{ }^{\circ} \mathrm{C}$ with stirring. After $10 \mathrm{~min}$, the amine $(2.0 \mathrm{mmol}$, for amine homocoupling) or the two amines $(1.0 \mathrm{mmol}$ and $1.5 \mathrm{mmol}$, for heterocoupling) were added with a syringe and the reaction was stirred for an additional $24 \mathrm{~h}$ under a flow of nitrogen. The mixture was then concentrated under reduced pressure and the residue purified by silica gel flash chromatography eluting with $98 / 2$ hexane/Et ${ }_{3} \mathrm{~N}$ (the column was first treated with pure $\mathrm{Et}_{3} \mathrm{~N}$ ).

General Procedure for Coupling of Alcohols and Amines: An ovendried Schlenk tube $(24 \times 150 \mathrm{~mm})$ was charged with $\mathrm{Co}_{2}(\mathrm{CO})_{8}(17.1 \mathrm{mg}$, $0.05 \mathrm{mmol})$, trioctylphosphine oxide (TOPO) $(20 \mathrm{mg}, 0.052 \mathrm{mmol})$ and a cylindrical stir bar $(10 \times 6 \mathrm{~mm})$. The tube was inserted into a Radleys carousel, vacuum was applied and the tube was filled with nitrogen (repeated 3 times). Degassed mesitylene $(2 \mathrm{~mL})$ was added with a syringe through the septum and the reaction vessel was heated to $164{ }^{\circ} \mathrm{C}$ with stirring. After $10 \mathrm{~min}$, the alcohol $(1.0 \mathrm{mmol})$ and the amine $(1.1 \mathrm{mmol})$ were added with a syringe and the reaction was stirred for an 
additional $24 \mathrm{~h}$ under a flow of nitrogen. The mixture was then concentrated under reduced pressure and the residue purified by silica gel flash chromatography eluting with $98 / 2$ hexane/ $\mathrm{Et}_{3} \mathrm{~N}$ (the column was first treated with pure $\mathrm{Et}_{3} \mathrm{~N}$ ).

\section{Acknowledgements}

We thank the Villum Fonden (grant 12380) for financial support.

Keywords: Amines $\cdot$ Cobalt $•$ Dehydrogenation $•$ Imines $•$ Nanoparticles

[1] a) A. Corma, J. Navas, M. J. Sabater, Chem. Rev. 2018, 118, 1410 1459; b) C. Gunanathan, D. Milstein, Science 2013, 341, 1229712; c) S. Bähn, S. Imm, L. Neubert, M. Zhang, H. Neumann, M. Beller, ChemCatChem 2011, 3, 1853-1864; d) Y. Obora, Y. Ishii, Synlett 2011, 30-51; e) R. Yamaguchi, K. Fujita, M. Zhu, Heterocycles 2010, 81, 1093-1140; f) G. E. Dobereiner, R. H. Crabtree, Chem. Rev. 2010, 110 $681-703$.

[2] a) G. A. Filonenko, R. van Putten, E. J. M. Hensen, E. A. Pidko, Chem. Soc. Rev. 2018, 47, 1459-1483; b) F. Kallmeier, R. Kempe, Angew. Chem. Int. Ed. 2018, 57, 46-60; Angew. Chem. 2018, 130, 48-63; c) B. Maji, M. K. Barman, Synthesis 2017, 49, 3377-3393; d) M. Garbe, K. Junge, M. Beller, Eur. J. Org. Chem. 2017, 4344-4362; e) E. Balaraman, A. Nandakumar, G. Jaiswal, M. K. Sahoo, Catal. Sci. Technol. 2017, 7, 3177-3195.

[3] S. M. A. H. Siddiki, T. Toyao, K. Shimizu, Green Chem. 2018, 20, 2933-2952.

[4] a) L.-P. He, T. Chen, D. Gong, Z. Lai, K.-W. Huang, Organometallics 2012, 31, 5208-5211; b) A. Prades, E. Peris, M. Albrecht, Organometallics 2011, 30, 1162-1167.

[5] a) D. Ainembabazi, N. An, J. C. Manayil, K. Wilson, A. F. Lee, A. M. Voutchkova-Kostal, ACS Catal. 2019, 9, 1055-1065; b) X. Jin, Y. Liu, Q. Lu, D. Yang, J. Sun, S. Qin, J. Zhang, J. Shen, C. Chu, R. Liu, Org Biomol. Chem. 2013, 11, 3776-3780; c) H.-A. Ho, K. Manna, A. D. Sadow, Angew. Chem. Int. Ed. 2012, 51, 8607-8610; Angew. Chem. 2012, 124, 8735-8738.

[6] T. W. Myers, L. A. Berben, J. Am. Chem. Soc. 2013, 135, 9988-9990.

[7] a) I. Dutta, S. Yadav, A. Sarbajna, S. De, M. Hölscher, W. Leitner, J. K. Bera, J. Am. Chem. Soc. 2018, 140, 8662-8666; b) K.-N. T. Tseng, A M. Rizzi, N. K. Szymczak, J. Am. Chem. Soc. 2013, 135, 16352-16355.

[8] a) P. T. K. Arachchige, H. Lee, C. S. Yi, J. Org. Chem. 2018, 83, 4932 4947; b) S. Kostera, B. Wyrzykiewicz, P. Pawluć, B. Marciniec, Dalton Trans. 2017, 46, 11552-11555; c) D. Hollmann, S. Bähn, A. Tillack, M. Beller, Angew. Chem. Int. Ed. 2007, 46, 8291-8294; Angew. Chem. 2007, 119, 8440-8444.

[9] a) M. Yamashita, Y. Moroe, T. Yano, K. Nozaki, Inorg. Chim. Acta, 2011, 369, 15-18; b) L. L. R. Lorentz-Petersen, P. Jensen, R. Madsen, Synthesis 2009, 4110-4112; c) O. Saidi, A. J. Blacker, M. M. Farah, S. P. Marsden, J. M. J. Williams, Angew. Chem. Int. Ed. 2009, 48, 73757378; Angew. Chem. 2009, 121, 7511-7514.

[10] a) K. Shimizu, K. Ohshima, Y. Tai, M. Tamura, A. Satsuma, Catal. Sci. Technol. 2012, 2, 730-738; b) K. Shimizu, K. Shimura, N. Tamagawa, M. Tamura, A. Satsuma, Appl. Catal. A 2012, 417-418, 37-42; c) W. He L. Wang, C. Sun, K. Wu, S. He, J. Chen, P. Wu, Z. Yu, Chem. Eur. J. 2011, 17, 13308-13317.

[11] a) L.-M. Wang, K. Kobayashi, M. Arisawa, S. Saito, H. Naka, Org. Lett. 2019, 21, 341-344; b) P. Linciano, M. Pizzetti, A. Porcheddu, M. Taddei, Synlett 2013, 2249-2254; c) K. Shimizu, K. Shimura, K. Ohshima, M. Tamura, A. Satsuma, Green Chem. 2011, 13, 3096-3100.
[12] a) H. Liu, G.-K. Chuah, S. Jaenicke, J. Catal. 2015, 329, 262-268; b) I. Kim, S. Itagaki, X. Jin, K. Yamaguchi, N. Mizuno, Catal. Sci. Technol. 2013, 3, 2397-2403.

[13] G. Zhang, S. K. Hanson, Org. Lett. 2013, 15, 650-653.

[14] K. Shimizu, K. Kon, M. Seto, K. Shimura, H. Yamazaki, J. N. Kondo, Green Chem. 2013, 15, 418-424.

[15] a) F. Bottaro, R. Madsen, ChemCatChem 2019, 11, 2707-2712; b) S. P. Midya, J. Pitchaimani, V. G. Landge, V. Madhu, E. Balaraman, Catal Sci. Technol. 2018, 8, 3469-3473; b) S. Shee, K. Ganguli, K. Jana, S. Kundu, Chem. Commun. 2018, 54, 6883-6886; c) S. P. Midya, V. G. Landge, M. K. Sahoo, J. Rana, E. Balaraman, Chem. Commun. 2018, 54, 90-93; d) P. Daw, S. Chakraborty, J. A. Garg, Y. Ben-David, D. Milstein, Angew. Chem. Int. Ed. 2016, 55, 14373-14377; Angew. Chem 2016, 128, 14585-14589; e) M. Mastalir, G. Tomsu, E. Pittenauer, G. Allmaier, K. Kirchner, Org. Lett. 2016, 18, 3462-3465; f) S. Rösler, M. Ertl, T. Irrgang, R. Kempe, Angew. Chem. Int. Ed. 2015, 54, 1504615050; Angew. Chem. 2015, 127, 15260-15264.

[16] A. Viola, J. Peron, K. Kazmierczak, M. Giraud, C. Michel, L. Sicard, N Perret, P. Beaunier, M. Sicard, M. Besson, J.-Y. Piquemal, Catal. Sci. Technol. 2018, 8, 562-572.

[17] a) K. Paudel, B. Pandey, S. Xu, D. K. Taylor, D. L. Tyer, C. L. Torres, S Gallagher, L. Kong, K. Ding, Org. Lett. 2018, 20, 4478-4481; b) S. Xu, L. M. Alhthlol, K. Paudel, E. Reinheimer, D. L. Tyer, D. K. Taylor, A. M. Smith, J. Holzmann, E. Lozano, K. Ding, Inorg. Chem. 2018, 57, 2394 2397

[18] B. Emayavaramban, P. Chakraborty, E. Manoury, R. Poli, B. Sundararaju, Org. Chem. Front. 2019, 6, 852-857.

[19] Z. Yin, H. Zeng, J. Wu, S. Zheng, G. Zhang, ACS Catal. 2016, 6, 65466550 .

[20] H. Chung, S. Han, Y. K. Chung, J. H. Park, Adv. Synth. Catal. 2018 $360,1267-1272$.

[21] For aerobic oxidation of primary amines into imines with a cobalt(II) catalyst containing a tetradentate ligand, see: S. Hazra, P. Pilania, M Deb, A. K. Kushawaha, A. J. Elias, Chem. Eur. J. 2018, 24, 1576615771.

[22] We have recently developed silver nanoparticles for dehydrogenation of primary alcohols into carboxylic acids, see: H. G. Ghalehshahi, R. Madsen, Chem. Eur. J. 2017, 23, 11920-11926.

[23] a) T. Song, Z. Ma, Y. Yang, ChemCatChem 2019, 11, 1313-1319; b) P. Büschelberger, E. Reyes-Rodriguez, C. Schöttle, J. Treptow, C Feldmann, A. J. von Wangelin, R. Wolf, Catal. Sci. Technol. 2018, 8, 2648-2653; c) S. Sandl, F. Schwarzhuber, S. Pöllath, J. Zweck, A. J. von Wangelin, Chem. Eur. J. 2018, 24, 3403-3407; d) J. Li, G. Liu, X. Long, G. Gao, J. Wu, F. Li, J. Catal. 2017, 355, 53-62; e) R. V. Jagadeesh, K. Murugesan, A. S. Alshammari, H. Neumann, M.-M. Pohl, J. Radnik, M. Beller, Science 2017, 358, 326-332; f) F. Peng, B. Sahoo, C. Kreyenschulte, H. Lund, M. Zeng, L. He, K. Junge, M. Beller, Chem Sci. 2017, 8, 6239-6246; g) T. Schwob, R. Kempe, Angew. Chem. Int Ed. 2016, 55, 15175-15179; Angew. Chem. 2016, 128, 15400-15404.

[24] a) K. Murugesan, M. Beller, R. V. Jagadeesh, Angew. Chem. Int. Ed. 2019, 58, 5064-5068; Angew. Chem. 2019, 131, 5118-5122; b) G. Jaiswal, V. G. Landge, D. Jagadeesan, E. Balaraman, Nat. Commun 2017, 8, 2147; c) R. V. Jagadeesh, A.-E. Surkus, H. Junge, M.-M. Pohl J. Radnik, J. Rabeah, H. Huan, V. Schünemann, A. Brückner, M. Beller Science 2013, 342, 1073-1076; d) K.-i. Shimizu, N. Imaiida, K. Kon, S. M. A. H. Siddiki, A. Satsuma, ACS Catal. 2013, 3, 998-1005; e) F. Alonso, P. Riente, M. Yus, Acc. Chem. Res. 2011, 44, 379-391; f) C. Gonzalez-Arellano, K. Yoshida, R. Luque, P. L. Gai, Green Chem. 2010, 12, 1281-1287.

[25] For recent reviews on catalytic methods for synthesis of imines, see: a) B. Chen, L. Wang, S. Gao, ACS Catal. 2015, 5, 5851-5876; b) M Largeron, Eur. J. Org. Chem. 2013, 5225-5235; c) R. D. Patil, S. Adimurthy, Asian J. Org. Chem. 2013, 2, 726-744.

[26] a) R. M. de Silva, V. Palshin, F. R. Fronczek, J. Hormes, C. S. S. R. Kumar, J. Phys. Chem. C 2007, 111, 10320-10328; b) H. T. Yang, Y. K. 
Su, C. M. Shen, T. Z. Yang, H. J. Gao, Surf. Interface Anal. 2004, 36, 155-160; c) V. F. Puntes, K. M. Krishnan, A. P. Alivisatos, Science 2001, 291, 2115-2117; d) D. P. Dinega, M. G. Bawendi, Angew. Chem. Int. Ed. 1999, 38, 1788-1791; Angew. Chem. 1999, 111, 1906-1909..

[27] a) M. A. Gertsen, V. I. Nikolaichik, V. V. Volkov, A. S. Avilov, S. P. Gubin, Crystallogr. Rep. 2017, 62, 960-965; b) Y. Bao, W. An, C. H. Turner, K. M. Krishnan, Langmuir 2010, 26, 478-483; c) J. Schällibaum, F. H. Dalla Torre, W. R. Caseri, J. F. Löffler, Nanoscale 2009, 1, 374-
381; d) A. Lagunas, C. Jimeno, D. Font, L. Solà, M. A. Pericàs, Langmuir 2006, 22, 3823-3829.

[28] a) W. Li, O. J. Borkiewicz, M. Saubanère, M.-L. Doublet, D. Flahaut, P. J. Chupas, K. W. Chapman, D. Dambournet, J. Phys. Chem. C 2018 122, 23861-23866; b) P. van Helden, I. M. Ciobîcă, R. L. J. Coetzer Catal. Today 2016, 261, 48-59; c) O. Kitakami, H. Sato, Y. Shimada, F. Sato, M. Tanaka, Phys. Rev. B 1997, 56, 13849-13854. 
Entry for the Table of Contents (Please choose one layout)

Layout 1:

\section{FULL PAPER}

Text for Table of Contents

Layout 2:

\section{FULL PAPER}

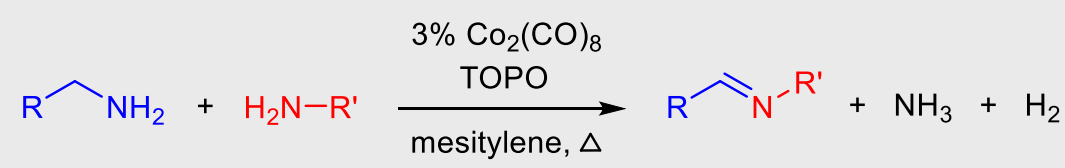

((Insert TOC Graphic here: $\max$. width: $5.5 \mathrm{~cm}$; max. height: $5.0 \mathrm{~cm})$ )
Author(s), Corresponding Author(s)*

Page No. - Page No.

Title

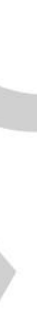

\section{Dehydrogenation}

F. Bottaro, A. Takallou, A. Chehaiber, $R$. Madsen*

\section{Page No. - Page No.}

\section{Cobalt-Catalyzed Dehydrogenative Coupling of Amines into Imines}

The acceptorless dehydrogenative coupling of primary amines into imines is achieved with dicobalt octacarbonyl as the precatalyst. The catalytically active species are in situ formed cobalt nanoparticles that can be recovered and used again. 